\title{
Firm-bank credit network, business cycle and macroprudential policy
}

\author{
Luca Riccetti*1 $^{*}$, Alberto Russo ${ }^{2,3}$, and Mauro Gallegati ${ }^{3}$ \\ ${ }^{1}$ Università degli Studi di Macerata, via Crescimbeni 14, 62100 Macerata, Italy \\ ${ }^{2}$ Universitat Jaume I, Av. Vicent Sos Baynat s.n., 12071 Castellón de la Plana, Spain \\ ${ }^{3}$ Università Politecnica delle Marche, piazzale Martelli 8, 60121 Ancona, Italy
}

\section{5th November 2020}

\begin{abstract}
We present an agent-based model to study firm-bank credit market interactions in different phases of the business cycle. The business cycle is exogenously set and it can give rise to various scenarios. Compared to other models in this literature strand, we improve the mechanism according to which the dividends are distributed, including the possibility of stock repurchase by firms. In addition, we locate firms and banks over a space and firms may ask credit to many banks, resulting in a complex spatial network. The model reproduces a long list of stylized facts and their dynamic evolution as described by the cross-correlations among model variables. The model allows us to test the effectiveness of rules designed by the current financial regulation, such as the Basel III countercyclical capital buffer. We find that the effectiveness of this rule changes in different business cycle environments and this should be considered by policy makers.
\end{abstract}

Keywords: Agent-based modeling, credit network, business cycle, financial regulation, macroprudential policy.

JEL classification codes: C63, E32, E52, G01.

${ }^{*}$ Corresponding author. E-mail: luca.riccetti@unimc.it 


\section{Introduction}

Financial accelerator mechanisms are well established in the recent literature, showing how business cycle fluctuations can be enlarged by self-reinforcing forces. Bernanke and Gertler $(1989,1990,1995)$ and Bernanke et al. (1999) show the presence of a positive feedback mechanism: a reduction of asset values held by the entrepreneurs generates an increase of the borrowers' leverage and subsequently of the risk premium, with a consequent contraction of the economic activity. Indeed, firms are less prone to invest because they compare a reduced expected profit with an increased cost of funding; therefore, reduced investments lead to a lower output in a vicious circle. The recent crisis, in countries like Italy, shows that a negative shock on firms' output makes banks less willing to loan funds, with a consequent credit crunch beside the increase of the interest rate. Riccetti et al. (2013) couple the explained financial accelerator, called "leverage" accelerator, with the "network-based" financial accelerator proposed by Delli Gatti et al. (2010). The latter accelerator highlights that the presence of a credit network may produce an avalanche of firms' bankruptcies: the bankruptcy of a firm may bring "bad debt" - i.e. non-performing loans - that affects the net worth of banks, which can also go bankrupt or, if they manage to survive, they will react to the deterioration of the net worth increasing the interest rate to all their borrowers (Stiglitz and Greenwald, 2003, p.145), making them incur additional difficulties in servicing debt and thus increasing the weakness of the whole non-financial sector, in another vicious circle. Riccetti et al. (2016) further enlarges these mechanisms adding the "stock market accelerator", also representing possible financial market bubbles, in order to build a triple financial accelerator.

Starting from the cited literature strand (Delli Gatti et al., 2010; Riccetti et al., 2013, 2016), in this paper we build an agent based macroeconomic model able to represent the firm-bank credit network under different phases of the business cycle. Differently from the cited papers, the business cycle is exogenous and can be set in order to reproduce various scenarios. Moreover, the current model performs a series of improving changes and refinements. In practice, we try both to build a model similar to the cited ones without some of the strong assumptions made in those models, and to reproduce some further stylized facts:

- Firstly, decisions about output production and capital structure are separated; with this mechanism, the production function does not necessarily need decreasing return to scale in order to stabilize the model's output and we use constant return to scale. 
- As for the capital structure, we improve the dividend mechanism including the possibility of stock repurchase by firms. The use of stock repurchase is very relevant for two reason. First, it makes the model more realistic. Indeed, in the last decades, stock repurchases are increasingly used in place of dividends (Fama and French, 2001). On these bases, Skinner (2008) suggests that repurchases are now the dominant form of payout. Moreover, "over the decade 2001-2010, the 500 corporations in the S\&P 500 Index (representing about $75 \%$ of US stock-market capitalization) expended not only $40 \%$ of their profits on cash dividends the normal mode of rewarding shareholders - but also another $54 \%$ on stock buybacks, the purpose of which is to give a manipulative boost to a company's own stock price" (Lazonick, 2013). Second, it helps us to prevent a too strong growth due to an excessive accumulation of internal resources which causes a reduction of firms and banks' defaults and reduced business cycle fluctuations. To avoid this excessive growth, while in Riccetti et al. (2013, 2016) we assumed decreasing return to scale, in the current model we adopt a stock repurchase mechanism, which makes the model much more realistic.

- Moreover, we allow banks to merge in order to avoid the presence of small "empty" banks (namely inactive banks that are "alive" but without customers).

- Another major change regards the structure of the credit market: firms and banks are located over a unitary space and firms may ask credit to multiple banks, therefore a complex spatial network arises. Again, this modeling choice is performed to make the model more realistic, in order to represent the stylized facts that the distribution of node degree is right-skewed with larger banks characterized by a higher number of links, and that larger banks supply credit both to large and small enterprises, while small banks supply credit only to (relatively) small and local enterprises.

- In addition, the interest rate mechanism is devised in order to consider the default probability of the firm asking for credit.

- Lastly, banks' credit supply is constrained by Basel III rules. This feature allows us to perform a simulation analysis on banking regulation, as done in some other agent-based models, such as Neuberger and Rissi (2012), Cincotti et al. (2012), Krug et al. (2015), da Silva and Lima (2017), Popoyan et al. (2017) and Riccetti et al. (2018). 
Agent-based models are particularly suited for such kind of investigation which involves the analysis of a multi-layered network of financial stocks and flows and its macroeconomic implications due to the dispersed interaction of heterogeneous agents (Tesfatsion and Judd, 2006). Last decades have been characterized by a blossoming of macroeconomic agent-based models: for example, Riccetti et al. (2015) proposed a macroeconomic model in which heterogeneous households, firms and banks interact on various markets through a decentralized matching protocol that successively has been employed in other papers in order to develop a fully fledged macroeconomic agent-based model,${ }^{1}$ like in Caiani et al. (2016). The model of Riccetti et al. (2015) showed that the financial leverage (especially bank exposure) is non-linearly related to the macroeconomic performance, given that as the leverage increases the economy tends to expand though with decreasing gains and up a certain threshold after which more leverage increases the probability of crises. The model is also able to endogenously generate business cycles as well as small and large crises. Other agent-based macro frameworks have been proposed, for instance in Dosi et al. (2010), Cincotti et al. (2010) and successive extensions of both papers.

One of the main ingredients of such kind of macro frameworks, which is at the same time one of the main advantages of using the agent-based methodology, is the presence of direct interaction, ${ }^{2}$ in particular regarding financial networks, which is a characterizing feature of the present paper. In this way it is possible to overcome a number of limitations arising from assuming the presence of a Representative Agent: "no financial markets (who is lending to whom?); no scope accordingly for excess indebtedness (who owes money to whom?) or for deleveraging (who is reducing their indebtedness to whom?); no problem of debt restructuring; no meaningful capital structures (since the single individual is bearing all the risk, it is obvious that nothing can depend on whether finance is provided in the form of debt or equity); no role for bankruptcy". (Stiglitz, 2011, p. 598). One of the first attempts to analyze the interplay between financial inter-linkages (with a static network) and the business cycle is in Delli Gatti et al. (2006), then extended in Delli Gatti et al. (2010) with a dynamically evolving network with firmbank credit relationships. The present paper has its roots in this modeling tradition, ${ }^{3}$ highlighting the fundamental role of credit interconnections and

\footnotetext{
${ }^{1}$ This research stream comes from previous attempts to develop models with heterogeneous agents which interact through decentralized mechanisms, as for instance in Russo et al. (2007).

${ }^{2}$ The typical mode of interaction in mainstream macro papers is instead indirect interaction, mediated by the price system.

${ }^{3}$ For a couple of examples including an empirical analysis of credit networks within an
} 
their relation with the characteristics of the business cycle. As explained above, the explicit description of the network structure of credit and financial markets allows us to investigate the working of the financial accelerator in a network economy, and then to take into account phenomena like financial contagion and bankruptcy chains.

The literature on financial contagion has stressed the role of agents' interactions and the endogenous formation of networks as key ingredients of systemic risk: while the increase of the number of links in a financial network can be a stabilizing force due to risk-sharing (Allen and Gale, 2000), the particular configuration of a growing network can also be destabilizing, possibly producing more non-performing loans and increasing the likelihood of default avalanches (Lux, 2016; Bottazzi et al., 2020); in other words, the financial system can exhibit a "robust yet fragile" behavior according to which stability prevails but catastrophic events can happen with a non-zero probability; financial network models can prove useful to reconstruct contagion dynamics and proposing appropriate macroprudential tools (Caccioli et al. 2014). The present paper extends the analysis performed in previous macro agent-based models to incorporate the role of financial regulation, specifically macroprudential policy, to mitigate financial instability mainly through the countercyclical capital buffer.

The remainder of the paper is organized as follows: in the next Section we present the model. Simulation results are reported in Section 3, while Section 4 proposes a macroprudential policy experiment on the countercyclical capital buffer. Finally, Section 5 concludes.

\section{The model}

Our economy is populated by firms and banks: firms are indexed by $i=$ $1,2, \ldots, I$ and produce consumption goods, while banks are indexed by $z=$ $1,2, \ldots, Z$ and extend credit to firms. The number of firms and banks is constant and they are uniformly spatially distributed on a line of length one. Moreover, there is a sketched central bank, while households (as final consumers, labor suppliers and banks' depositors) are in the background.

We focus on the credit market where firms and banks interact. A shock to a firm affects the credit relationship between the firm and the bank: if the shock is large enough, the firm may be unable to fulfill debt commitments and may go bankrupt. In a networked economy, the bankruptcy of a firm may bring "bad debt" that reduces the net worth of banks that, in turn, may go bankrupt. The rising "bad debt" and the deterioration of the net

agent-based framework, see Bargigli et al. (2014, 2019). 
worth have two consequences: a reduction of credit supply and an increase of the interest rate applied by the banking system to all the borrowers, with a larger risk premium due to the lack of trust in a weaker non-financial sector (namely, increasing banks' risk aversion). Hence, borrowers may incur additional difficulties in servicing debt, thus increasing the weakness of the whole non-financial sector and the number of bankruptcies itself. We will describe the credit market in details in Section 2.3.

We do not explicitly model consumption, labor and deposit markets, which are in the background. The consumption goods market, in which households represent the demand side and firms are on the supply side, influences firms' profits. The output of the interaction in the consumption market is summarized by the unitary operating profit op (before financial costs paid on bank loans) - see Section 2.1 for details - assuming that unsold goods are thrown away (no inventories). A negative unitary operating profit represents a circumstance in which a weak consumption goods demand reduces the revenues below the operating cost (that also implicitly includes the output of the labor market), causing a loss for the firm.

The deposit market is also in the background: the amount of deposits (equal to bank's total liabilities) is set equal to the extended credit. ${ }^{4}$ Indeed, bank's balance sheet is composed by cash plus credit on the asset side, and deposits plus net worth on the other side, assuming cash equal to net worth and deposits equal to extended credit. In this market, the price, that is the interest rate paid by banks to depositors, is exogenously set by the parameter $r_{t}^{D}$ (equal for all banks).

\section{$2.1 \quad$ Firms}

Firms borrow money from different banks, produce goods and sell them to households. The production function is an increasing function of the firm total capital $K$. In particular, the production $Y$ of firm $i$ at time $t$ is:

$$
Y_{i, t}=\phi K_{i, t}
$$

where $\phi \geq 1$ is a parameter that we set uniform across firms. $K_{i, t}$ corresponds to the sum of net worth $A_{i, t}$ and debt $B_{i, t}{ }^{5}$.

\footnotetext{
${ }^{4}$ This is a simplifying assumption that we make in order to keep the banking system as simple as possible, in absence of both the interbank market and the advances from the central bank to commercial banks. This is just an approximation of a fully decentralized banking system. Anyway, we do not think that a more detailed description of liquidity management in the banking sector could modify model dynamics significantly.

${ }^{5}$ Compared to Delli Gatti et al. (2010) and Riccetti et al. (2013), we do not assume the presence of decreasing returns to scale, that is the "financially constrained output
} 
However, differently from Riccetti et al. (2013), in the current model the decisions about output production and capital structure are separated. First of all, we do not determine $Y$ starting from $K$, but we follow the opposite way: we define a production target $Y^{*}$ as follows:

$$
Y_{i, t}^{*}= \begin{cases}Y_{i, t-1}^{*} \cdot[1-U(0, a d j)], & \text { if } o p_{i, t-1}<0 \\ Y_{i, t-1}^{*} \cdot[1+U(0, a d j)], & \text { if } o p_{i, t-1} \geq 0\end{cases}
$$

In words, the firm decides to expand its output target if in the previous period it obtained a positive (unitary) operating profit op and vice versa. In reality, Equation 2 could be generalized using the expected unitary operating profit $o p_{i, t}^{e}$. In practice, we decide to use simple adaptive expectations for our agents; therefore, in this case: $o p_{i, t}^{e}=o p_{i, t-1}$. The target amount changes randomly by a percentage between 0 and $a d j$. adj is a parameter that sets the maximum percentage change between the two periods.

The total capital target $K^{*}$ is determined by simply inverting Equation 1: $K_{i, t}^{*}=Y_{i, t}^{*} / \phi$.

Then, the firm tries to increase the owners' revenues per unit of net worth by improving the capital structure, that is the relative composition of debt and net worth. Leverage is given by the fraction $L=\frac{B}{A}$ and, following the (Dynamic) Trade-Off theory ${ }^{6}$, firms fix a target leverage $L^{*}$ :

$$
L_{i, t}^{*}= \begin{cases}L_{i, t-1}^{*} \cdot[1-U(0, a d j)], & \text { if } \phi \cdot o p_{i, t-1} \leq r_{i, t-1} \\ L_{i, t-1}^{*} \cdot[1+U(0, a d j)], & \text { if } \phi \cdot o p_{i, t-1}>r_{i, t-1}\end{cases}
$$

where $r_{i, t-1}$ is the interest rate on the previous period bank loan. In other words, the firm wants to increase its leverage if the profit per unit of capital is larger than the cost of debt $r_{i, t-1}$.

Given the target capital $K^{*}$ and the target leverage $L^{*}$, firms compute the target net worth:

$$
A_{i, t}^{*}=\frac{K_{i, t}^{*}}{1+L_{i, t}^{*}}
$$

function" where $K_{i, t}^{\beta}$ with $0<\beta<1$. Even if the model can be calibrated also (with a parameter $0<\beta<1$ ), in this case we are implicitly assuming constant returns to scale because the economic theory and many empirical studies suggest that firms often present (at least till a large level of size and complexity) increasing or constant returns to scale. Moreover, in this way, we avoid the presence of a further parameter.

${ }^{6}$ According to the Dynamic Trade-off theory, firms have long-run leverage targets, but they do not immediately reach them; rather they adjust toward them during some periods. In our model, firms try to reach the target immediately, even if they could miss it because banks do not supply the required credit with a consequent leverage below the target, or because net worth is below its target and leverage goes above the target as explained in Equations 4, 5 and 6. For a review on the Dynamic Trade-off theory, see for instance Flannery and Rangan (2006), Frank and Goyal (2008, 2015), and Riccetti et al. (2013). 
Consequently, firms calculate the amount of dividends and stocks repurchases $^{7}$ :

$$
\operatorname{Div}_{i, t}=\max \left(A_{i, t-1}-A_{i, t}^{*}, 0\right)
$$

Hence, firm $i$ does not distribute dividends (and does not perform stocks repurchase) if its net worth is smaller than its target net worth. Now, it presents a new amount of net worth $A_{i, t} \leq A_{i, t}^{*}$ that can be used in the current period in order to produce goods. Starting from this value, firm $i$ can compute its target debt $B^{*}$ as:

$$
B_{i, t}^{*}=\min \left(K_{i, t}^{*}-A_{i, t}, 10 \cdot A_{i, t}\right)
$$

where $10 \cdot A_{i, t}$ represents a cap for the required debt equal to a leverage value of 10, assuming that banks refuse to lend an excessive amount of credit ${ }^{8}$. Indeed, the target capital $K^{*}$ could remain relatively high after a period of high losses for a firm which presents a level of net worth $A$ below its target. In this case, the firm could require a very high amount of debt in order to reach the target capital, thus implying a very high leverage level. Therefore, in order to prevent an excessive leverage, we fix a cap to the target debt.

Then, firms interact with banks on the credit market and obtain an amount of credit $B \leq B^{*}$. We assume that the nominal debt requested at time $t$ is fully reimbursed at time $t+1$, together with the interest payment. The details of the credit mechanism will be explained in Section 2.3. Firm $i$ pays an interest rate $r_{i, t}$ which is determined by the following equation:

$$
r_{i, t}^{F}=r_{t}^{B C}+r p_{i, t}+0.1 \cdot c+\mu
$$

where $r_{t}^{B C}$ is the base policy rate set by the Central Bank (moreover, we assume that the interest rate paid by banks on deposits $r_{t}^{D}$ is equal to $r_{t}^{B C}$ ), $r p_{i, t}$ is the credit risk premium, $c$ is the parameter representing the costs paid by banks (see Equation 17), and $\mu$ is a mark-up parameter. Therefore, the only endogenous component in the interest rate is given by the credit risk premium, while the other components are exogenous for the firm. Specifically, the risk premium is equal to:

$$
r p_{i, t}=P D_{i, t}^{e} \cdot\left(1+\frac{b a d_{t-1}}{B_{t-1}}\right)
$$

\footnotetext{
${ }^{7}$ The stocks repurchase mechanism is here equivalent to an extraordinary dividend. Moreover, dividends paid by the firms to the households are then not explicitly modeled as a component of the aggregate demand, which is exogenously set.

${ }^{8}$ This credit rationing mechanism is never applied in our simulations. In practice, firms never reach a leverage equal to 4 .
} 
where $P D_{i, t}^{e}$ is the expected probability of default of firm $i$, and $\frac{b a d_{t-1}}{B_{t-1}}$ is the percentage of aggregate non-performing loans (bad debt) on the credit amount extended by the banking system to the firms in the previous period. In this component, we merge an idiosyncratic information on the health of firm $i$ with an aggregate information on the health of the overall economic system. Indeed, the risk premium decreases with the financial soundness of the firm (lower PD) as well as with the financial soundness of the economy (lower percentage of non performing loans), and vice versa. In particular, the expected PD is computed as the exact probability of default of the firm, but using inputs adaptively (as done for all the other expected values), namely using the values of leverage and interest rate paid by the firm in the previous period. In practice, $P D_{i, t}^{e}=P D_{i, t-1}$, and the latter is the value taken from the cumulative distribution function of a $N_{i, t}\left(\alpha_{t}, s t d_{o p}\right)$ at the value equal to $\frac{r_{i, t-1}^{F} \cdot L_{i, t-1}-1}{\phi \cdot\left(1+L_{i, t-1}\right)}$. In other words, this is the default probability for a firm with leverage equal to $L_{i, t-1}$ and paying an interest rate on debt equal to $r_{i, t-1}^{F}$. The use of a Normal distribution with $\alpha_{t}$ mean and $s t d_{o p}$ standard deviation is due to the profit mechanism of the model that we are going to explain.

Given the received credit, firms have a total capital $K=A+B$ and produce $Y$ according to Equation 1. On the produced output $Y$, firms obtain a unitary operating profit $o p$. A high realization of $o p_{i, t}$ can be thought of as a regime of high demand which drives up the relative gain of the commodity in question, while a low realization of $o p_{i, t}$ can be thought of as a regime of low demand that may imply losses and even push the firm to the bankruptcy. $o p_{i, t}$ is a random number drawn by $N_{i, t}\left(\alpha_{t}, s t d_{o p}\right)$, that is a Normal distribution with standard deviation equal to $s t d_{o p}$, and mean equal to $\alpha_{t}$ that is a variable representing the business cycle common to all firms. Indeed, $\alpha$ is modeled as an auto-regressive (AR) function calibrated on the GDP of some countries, namely Germany and Japan, in which the firm-bank relationship on the credit market is very relevant for the funding of firms (differently from other countries in which the funding is more related to a direct access to financial markets). Performing some analyses on Germany and Japan quarterly seasonally adjusted GDP time-series from 1961:1 to 2018:3, downloaded from Federal Reserve Economic Data (FRED), we find that German GDP can be modeled with an $\mathrm{AR}(1)$ with autoregressive parameter equal to 0.84 (p-value largely below 1\%), or with an AR(2), while Japan GDP can be modeled with an $\mathrm{AR}(1)$ with autoregressive parameter equal to 0.93 (p-value largely below $1 \%$ too). Consequently, we decide to model our variable $\alpha$ following an $\mathrm{AR}(1)$ with autoregressive parameter equal to 0.9 , that is a value near to the real Japanese value and between the two estimated values. In particular:

$$
\alpha_{t}=\alpha_{0}+b \cdot\left(\alpha_{t-1}-\alpha_{0}\right)+N_{t}\left(0, s t d_{c y c}\right)
$$


where $b$ is the already cited $\operatorname{AR}(1)$ parameter set at 0.9 and the error term is drawn from a Normal with zero mean and $s t d_{c y c}$ standard deviation. Moreover, we also perform a set of simulations with $b=0.8$, that is near to the real parameter value estimated on German data. However, the model can perform analyses on different economies (with different gdp time series) simply modifying the value of parameter $b, \alpha_{0}, s t d_{c y c}$, or the AR structure of Equation 9.

Given the unitary operating profit, we can compute the overall profit $\Pi$ of the firm subtracting from the operating profit the interests paid on the debt:

$$
\Pi_{i, t}=o p_{i, t} \cdot Y_{i, t}-r_{i, t}^{F} \cdot B_{i, t}
$$

Profits $\left(\Pi_{i, t}\right)$ determine firms' net worth:

$$
A_{i, t}=A_{i, t}+\Pi_{i, t}
$$

The firm goes bankrupt if $A_{i, t}<0$, i.e. when it incurs a loss (negative profit) and the loss is big enough to deplete net worth: $\Pi_{i, t} \leq-A_{i, t}$. Now, there are two possibilities. If the firm is still alive, it adjusts its net worth eventually subtracting the amount $D i v_{i, t}$, representing dividends and stocks repurchases as described in Equation 5.

Otherwise, if the firm goes bankrupt, there are two consequences. First, banks which lent money to that firm compute a bad debt bad on the correspondent loan. The amount of the bad debt for bank $z$ from firm $i$ is equal to the extended loan multiplied by the loss given default rate ( $L g d$, that is 1 less the recovery rate). The $L g d$ is computed as follows:

$$
\operatorname{Lgd}_{i, t}=-\max \left(\frac{A_{i, t}+\Pi_{i, t}}{B_{i, t}}-l e ;-1\right)
$$

where le is a parameter that represents the percentage amount for the legal expenditure. Therefore, the bad debt for bank $z$ from firm $i$ is equal to:

$$
\operatorname{bad}_{z, i, t}=B_{z, i, t} \cdot L g d_{i, t}
$$

Second, we assume that a new firm enters in the market with a net worth equal to the median net worth of the survived firms.

\section{$2.2 \quad$ Banks}

As already explained, banks extend credit to firms. The interest rate set by banks was explained in the previous Section. The amount that banks can supply is determined with the following equation:

$$
B_{z, t}^{\max }=A_{z, t} \cdot\left(\frac{100}{6+C C B_{t}}\right)
$$


where $0 \leq C C B_{t} \leq 2.5$ is the countercyclical capital buffer ${ }^{9}$ set by the Central Bank - we will discuss the setting of this buffer in detail in Section 4. Therefore, the credit that can be extended is an increasing function of the net worth of the bank. The value 6 is taken by the Basel III rule that requires a minimum Tier 1 capital equal to the $6 \%$ of the risk weighted assets (we are implicitly assuming that all loans have a risk weight equal to 1, and that our net worth $A_{z, t}$ corresponds to the Tier 1 capital).

Moreover, banks have a further bound in the maximum exposure to a single counterpart. This is fixed with the following equation:

$$
B_{z, i, t}^{\max }=0.25 \cdot A_{z, t}
$$

indeed, a Basel III rule states that a single exposure can not exceed the $25 \%$ of the Tier 1 capital $^{10}$.

Banks' net worth $A_{z, t}$ evolves in the following way:

$$
A_{z, t+1}=A_{z, t}+\operatorname{Pr}_{z, t}-\operatorname{Div} z, t
$$

where $\operatorname{Pr}_{z, t}$ is bank $z$ profit at time $t$, and $D i v_{z, t}$ is the amount of dividend paid by the bank to its shareholders. In particular, $P r_{z, t}$ is given by:

$$
\operatorname{Pr}_{z, t}=\sum r_{i, t}^{F} \cdot B_{i, t}^{n d}-r_{t}^{D} \cdot D_{z, t}-c \cdot A_{z, t}-\operatorname{bad}_{z, t}
$$

where $r_{i, t}^{F}$ is the interest rate paid on the credit $B_{i, t}^{n d}$ by firm $i$ that has not gone bankrupt, $r_{t}^{D}$ is the interest rate paid by the bank on its deposits $D_{z, t}$, $c \cdot A_{z, t}$ are the costs paid by the bank determined as a percentage $c$ of the net worth of the bank, and $b a d_{z, t}$ is the sum of the losses due to all non performing loans computed on every defaulted firm that received a credit from bank $z$ (see Equation 13). As already said, we assume $r_{t}^{D}=r_{t}^{B C}$ and $D_{z, t}=\sum B_{z, i, t}$.

Dividends Div $_{z, t}$ are computed only for banks that obtain positive profits $\left(\operatorname{Pr}_{z, t}>0\right)$ :

$$
\operatorname{Div}_{z, t}=P r_{z, t} \cdot d b_{z, t}
$$

where $d b_{z, t}$ is the percentage of non retained profit computed as:

$$
d b_{z, t}=1-\left(L_{z, t}^{B}-5\right) \cdot 0.1
$$

where $L_{z, t}^{B}$ is the leverage of the bank computed as $L^{B}=\frac{D}{A}$, with a cap at 1 and a floor at 0 . In other words, the percentage of distributed profit is low if

\footnotetext{
${ }^{9}$ https://www.bis.org/bcbs/ccyb/

${ }^{10}$ https://www.bis.org/fsi/fsisummaries/largeexpos.htm
} 
the bank has a high leverage, because it needs more net worth in order to be less financially fragile and to be able to extend further credit. In particular, dividends go to zero when $L_{z, t}^{B} \geq 15$, that is near to the maximum possible leverage computed using Equation 14 (assuming a $C C B_{t}$ near or equal to zero). Vice versa, the percentage of distributed profits is high when the bank has a low leverage (till $100 \%$ when the leverage is equal or below 5 ).

The bank goes bankrupt if $A_{z, t+1}<0$, i.e. when it incurs a loss (negative profit) and the loss is big enough to deplete net worth: $\Pi_{z, t} \leq-A_{z, t}$. If some banks go bankrupt, there are two consequences. First, we assume a one-to-one replacement, with new banks entering in the market with a net worth equal to twice the median net worth of the survived firms ${ }^{11}$. Second, losses are distributed on the banking system. In particular, we define the losses $\operatorname{Loss}_{t}=\sum A_{z, t}^{d}$, where $A_{z, t}^{d}$ is the (negative) net worth of a defaulted banks. $\operatorname{Loss} B_{t}$ is proportionally distributed on the net worth of each survived banks ${ }^{12}$. That is:

$$
A_{z, t}=A_{z, t} \cdot\left(1-\operatorname{Loss}_{t} \cdot \frac{A_{z, t}}{\sum A_{z, t}}\right)
$$

The mechanism to ask to the banking system to cover the losses in order not to lose the trust of depositors in the banking system is applied in various forms. Indeed, in many countries losses are often covered by deposit guaranteed schemes (for instance in the European Union, depositors are guaranteed till the amount of Euro 100,000), or healthy banks are sometimes forced to buy defaulting banks. Even the European Bank Recovery and Resolution Directive (BRRD), that imposes the bail-in tool, includes an intervention of a Resolution Fund paid by banks ${ }^{13}$.

\footnotetext{
${ }^{11}$ We decide to use twice the median net worth of the firms, because the median is usually smaller than the mean and firms are usually smaller than banks. In this way we reach two effects: on the one hand, new entrants are small new banks; on the other hand, new banks have enough money to provide credit to firms, thus avoiding the phenomena of "empty" banks that have to be merged in the following period. Moreover, we want to stress that the number of bank defaults is small, and that we find similar results when, as a robustness check, we perform simulations halving the net worth of new banks (that is, a net worth equal to the median net worth of the survived firms).

${ }^{12} \mathrm{We}$ also set a rule as a backstop against a huge disruption of the capital of the banking system. If $\operatorname{Loss} B_{t}>0.5 \sum A_{z, t}$, the losses are very large for the banking system (above the $50 \%$ of the overall net worth of the banking system) and the Government covers them in order to prevent a systemic crisis. In practice, in all the performed simulations, the Government is never required to intervene, given the low number of bank defaults and the consequent small loss for the banking system compared to its total net worth (less than $5 \%)$.

${ }^{13}$ The intervention of a Resolution Fund is up to a maximum of $5 \%$ of total liabilities,
} 
There could be the presence of banks with a very small net worth. In these cases, banks could be too small to satisfy firms' credit requests and they could remain without customers. Moreover, in every period their net worth further decrease because, without revenues, profits turn to be negative (even if these negative profits, equal to a fraction of the net worth as determined by Equation 17, are not large enough to cause a bankruptcy). In order to avoid the presence of "empty" banks without customers, we imposed that these banks have to merge: the "empty" bank with the largest net worth sum the net worth of all the "empty" banks and the others are replaced by new banks. If there is only one "empty" bank, it is considered as defaulted and its net worth is distributed proportionally to the survived banks. In practice, the net worth of the "empty" bank is subtracted to LossB.

In the next subsection, we will describe the credit interaction mechanism between firms and banks.

\subsection{Credit market}

Firms and banks interact in the credit market. Firms are allowed to borrow from different banks. In the language of graph theory, each firm/bank is represented by a node on the graph and the credit exposures are represented by links. These links are directed (from banks to firms) and weighted (the amount lent), and the network is said "bipartite".

We use a matching mechanism similar to Riccetti et al. (2013b, 2015), even if in this case all banks fix the same interest rate and, therefore, firms cannot choose the best counterpart in term of the interest rate. Moreover, in the current model, we provide a spatial location on a line of length one to each firm and bank. In particular, they are evenly spaced (with space $1 / Z$ for banks and $1 / I$ for firms). The spatial location implies that firms and banks have a distance that can be interpreted both as "operational" and "functional" (see, for instance, Alessandrini et al., 2009, and references therein).

The matching mechanism works as follows. At the beginning, a random list of agents in the demand side, namely firms, is set. Then, the first firm in the list observes all banks and chooses the bank that is able to supply the largest amount of credit. Indeed, we assume that firms prefer to reduce the number of lenders, because they aim at minimizing the investigation/preliminary costs (for due diligence, background checks, etc.). In the case that more than one bank supply the same maximum amount, for instance when many

subordinated to the condition that at least $8 \%$ of total liabilities have already been subject to bail-in mechanisms. 
banks are able to supply the whole credit amount required by the firm $B^{*}$, the firm chooses the nearest bank. This "nearest rule" is chosen in order to mimic a real behavior, usually found in the banking and finance literature. Indeed, for instance, Brevoort and Hannan (2006) find that the probability of a bank lending in a given area decreases with physical distance from the nearest office of that bank. After that, the second firm on the list performs the same activity. The process iterates till the end of the list. Then, a new random list of firms is set and the whole matching mechanism goes on until no further matches are feasible either because firms obtain all the desired credit or because banks cannot extend more credit (or they can lend an amount smaller than the $1 \%$ of the credit initially required by the firm: in this case we assume that the firm is not interested in receiving a so small amount) since they have reached their regulatory maximum level set by Equations 14 and 15 .

The structure of the network of credit relationships evolves endogenously. Large banks are able to supply large amounts of credit to big firms. As a consequence, their profits go up and their net worth grows, making room for even more partners. This self-reinforcing mechanism gives rise to an endogenous evolution of the credit network that mimics two stylized facts: (i) the distribution of node degree is right-skewed with larger banks characterized by a higher number of links (the so-called "hubs"); (ii) larger banks supply credit both to large and small enterprises, while small banks supply credit only to (relatively) small and local enterprises.

\section{Simulations}

We study the model by means of computer simulations. We assume that our economy is composed by 500 firms and 20 banks. Simulations last 500 periods. We discard the first 100 simulation periods in order to get rid of transient dynamics.

At time $t=1$, we set the net worth of each firm and bank to 10. We assume that, when a firm goes bankrupt, it is replaced by a new one with net worth equal to the median of surviving firms, while when a bank defaults it is replaced by a new one with net worth equal to the double of the median net worth of surviving firms.

As already explained in Section 2.1, we calibrate the parameters in Equation 9 on German and Japanese data. In particular we set: $\alpha_{0}=2 \%, b=0.9$, $s t d_{c y c}=0.5 \%$. Based on these values of the parameters, we reproduce a business cycle similar to that of the two selected countries. Moreover, we validate the calibration on the time series of the manufacturing production, given that 
our model only considers the manufacturing sector (and, consequently, the credit market between firms and banks, excluding house mortgages and consumer credit). Indeed, in the same analyzed period (from 1961:1 to 2018:3), the manufacturing production follows an $\mathrm{AR}(1)$ with autoregressive parameter equal to 0.33 (p-value largely below 1\%) in Germany, and an $\operatorname{AR}(1)$ with autoregressive parameter equal to 0.52 (p-value largely below $1 \%$ too) in Japan, and our simulation outputs present an $\mathrm{AR}(1)$ autoregressive parameter often close to those values (even if in the 50 Monte Carlo replication of the baseline parameter setting, the estimated $\mathrm{AR}(1)$ parameter on our time series ranges from a minimum of 0.09 to a maximum of 0.89 ).

The other parameters are also set in order to obtain values comparable to actual time series, as aggregate bad debt on total loans (we will call it "bad debt ratio"), mean loss given default rate, and mean firm leverage, according to an ex-post validation procedure ${ }^{14}$. Moreover, the central bank policy rate $r^{B C}$ (see Equation 7 ) is fixed at $1 \%$, and the countercyclical capital buffer $C C B$ (see Equation 14) is set at 1.25, so it is time-invariant and not "countercyclical" in these simulations. The setting of a truly time varying "countercyclical" buffer, $C C B_{t}$, will be analysed in the policy experiment that we will perform in Section 4.

\subsection{Baseline model results}

In this section we report the result of 50 Monte Carlo simulations performed on the baseline setting. We firstly discuss the output of a single simulation and, then, we show the dynamics of the system through the average crosscorrelation function computed on all the 50 simulations.

Figure 1 displays the output of a simulation. The first panel shows different shapes of business cycles, including a large crisis around period 450 . During the large crisis, the amount of non-performing loans and the lossgiven default rate largely increase (third panel in the first and in the third line, respectively), consequently there are two bank defaults (second panel in the third line), and the equity of the banking sector largely decreases (second panel in the second line). Therefore, firms become relatively larger compared to the banking sector (first panel in the second line), and a credit crunch follows (second panel in the first line). Moreover, the high bad debt signals to the banking system the presence of a downturn, then the credit risk premium increases (see Equation 8) and the interest rate grows (first panel in the third line). Some firms are forced to reduce the leverage because

\footnotetext{
${ }^{14}$ In particular, we fix $\phi=3$ (eq.1), $c=5 \%$ (eq.7 and 17), $\mu=1 \%$ (eq.7), $s t d_{o p}=5 \%$, $s t d_{c y c}=0.5 \%$ (eq.9), $a d j=10 \%$ (eq.2 and 3), le $=20 \%$ (eq.12).
} 
of the credit crunch and some others decide to reduce the leverage due to the higher interest rates: in the end, firms reduce the amount of external finance (third panel in the second line). Consequently, firms have to reduce their investments, leading to a lower output, lower profits, and yet again lower investments, in a vicious circle, further reducing the amount of internal funds. All in all, the leverage cycle enlarges the business fluctuations. These mechanisms are at work also in the smaller downturns of the business cycle (see, for instance, the downturns after period 100, or before period 200, or around period 400).

To better study the dynamics of the economic system, we analyze the cross-correlation functions among main variables. Moreover, we compute them on all the 50 simulations in order to have a robust result.

As shown in Figure 2, in the growing phase of the business cycle, both firms' leverage and bad debt go down (first and second panel in the third line). We want to stress the fact that the model reproduces an anti-cyclical firm leverage (at time $\mathrm{t}=0$ in the cross-correlation), as often found in the empirical evidence. Therefore, firms enlarge their debts in order to restore the leverage target and to exploit the willingness of the banks to lend money at a low interest rate level (given the low bad debt rate) and in the subsequent periods firms' leverage grows (again first panel in the third line, cross-correlations in the right side of the panel). In other words, while a growing debt is not worrying during the growing phase, due to a growth of the net worth growth even stronger than debt growth (lowering leverage), large debt becomes a problem when the cycle reverts deflating the net worth value and increasing the leverage. In the growing phase, debt increases boost production, but after a while this leads to growing instability that reverts the business cycle. Then, a higher leverage is associated with a higher interest rate and a higher bad debt (first panel in second and first line respectively). The latter two variables (mean interest rate and bad debt) are highly positively correlated: a higher interest rate increases firm defaults in that period and in the subsequent ones, and a higher bad debt increases the interest rate in the subsequent periods (second panel in the second line). Because of these vicious circles (positive feedback mechanisms), bad debt is highly autocorrelated (second panel in the first line) and largely correlated to the loss given default rate: in the downturns of the business cycle, the increase of the probability of default of firms is associated with the increase of the loss given default rate (third panel in the second line), as shown by empirical data. The third panel of the first line shows the positive cross-correlations between bad debt and bank defaults: large credit losses increase the probability of a bank default in the same and in the following periods, while a bank default damages the "real" economy because of the consequent credit crunch, as empirically 
Figure 1: The output of a simulation.
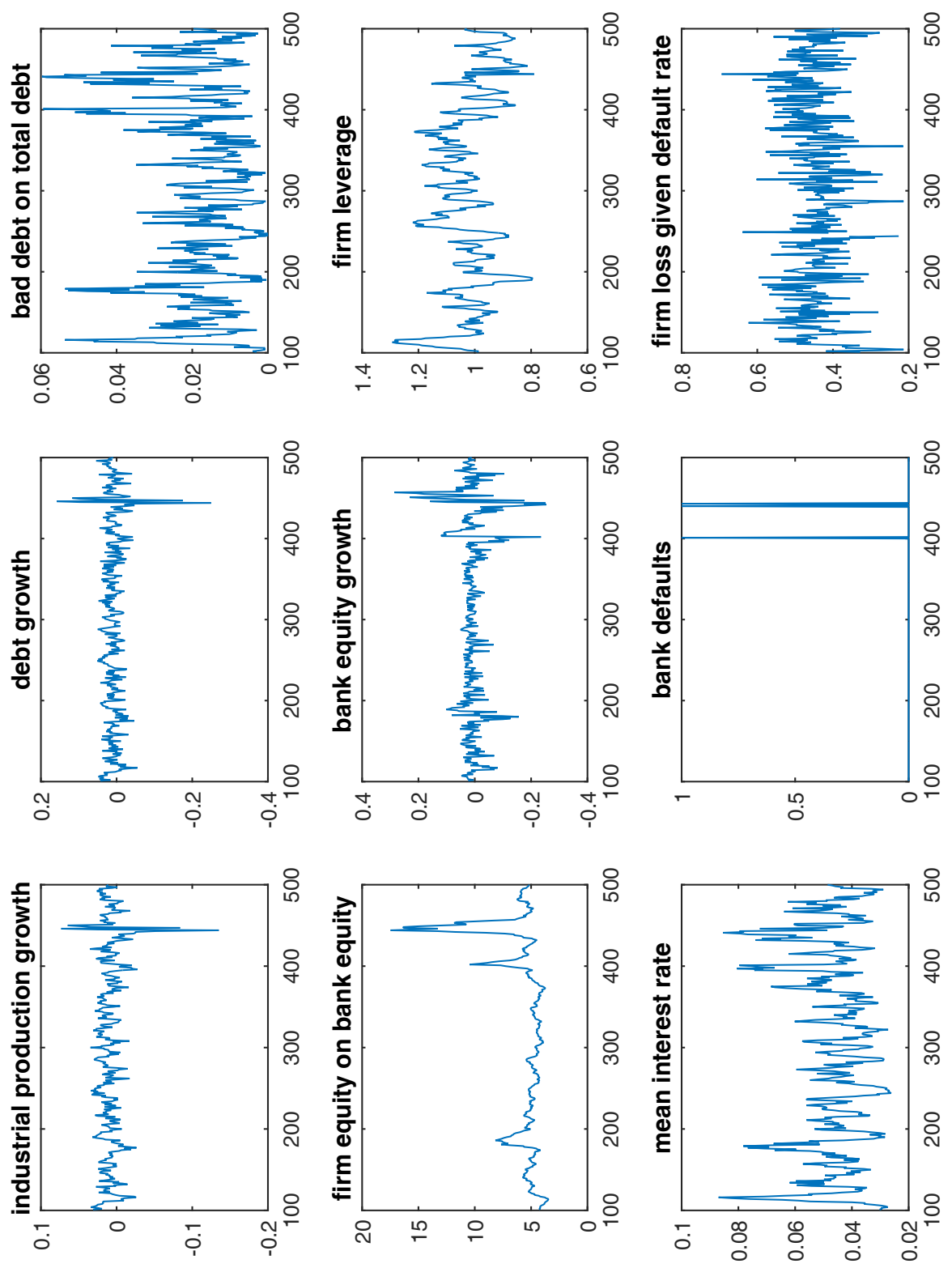
found in the studies on the financial crises. Last, in our model, bad debt is positively correlated to bank-firm credit network density. This is coarsely the consequence of the mechanisms implemented in the model: when the economy is growing and the banking system is robust, firms usually manage to obtain the required credit by a single bank; instead, in presence of a downturn of the business cycle, banks suffer losses that reduce their capital and prevent them to be able to extend large loans; therefore, some firms have to ask funds to many banks in order to obtain the required credit and the credit network becomes denser. This feature of the model should be verified with empirical data, in order to understand if the firm-bank credit network density is really positively correlated with the bad debt level, or if it is negatively correlated (for instance, because few banks are willing to lend money), or if it is uncorrelated. In our opinion, this feature could be realistic because, during crises, banks could prefer multiple lending in order to increase lending portfolio diversification (or, equivalently, to reduce portfolio concentration risk), and some banks could exploit the good signal obtained by the fact that another bank has already extended credit to the requiring firm evaluating it as financially reliable ${ }^{15}$. Last, as reported in Fig.3, simulations show the emergence of a network in which large banks are characterized by a high connection degree, ${ }^{16}$ while small banks present a smaller degree with local customers only. However, the model works almost in the same way even without placing banks and firms in an Hotelling line. Indeed, without the spatial dimension, we obtain that: (i) all macroeconomic outputs are the same, and (ii) bigger banks always present a higher number of connections compared to smaller banks. We insert the spatial dimension in order to obtain two further refinements of the second exposed feature. First, the range of the degree distribution is usually larger when firms and banks are placed in an Hotelling line. Indeed, the average (computed on 50 Monte Carlo simulations for each scenario) maximum number of banks' degree is 84.06 when the spatial dimension is included versus 70.87 otherwise, whereas the average minimum of banks' degree is almost the same (2.43 versus 2.92 respectively). Moreover, the average median is 16.68 versus 19.66, confirming the presence of a higher positive skewness in the case of spatial dimension.

\footnotetext{
${ }^{15}$ Tutino et al. (2017), observing the Italian empirical evidence during the financial and sovereign crises, that is in 2009-2011-2012, show that "while larger intermediaries and commercial banks registered a contraction of the loans to customers, smaller banks, cooperative intermediaries and popular banks continued to perform positively in terms of lending to customers". Given that small banks extend credits of relatively small amount, this feature could confirm our guess.

${ }^{16}$ For the empirical evidence on this and other stylized facts on bank-firm credit networks, see Bottazzi et al. 2020.
} 
As an example, Figure 3 shows the banks' degree distribution at the end of the two simulations with and without the spatial dimension. Second, we represent the stylized fact that big banks serve a large number of firms globally, while small banks present a lower number of connections and serve firms locally (see, for instance, Figure 4).

\section{Countercyclical capital buffer}

In this section we simulate the model with a time-varying countercyclical capital buffer. The $C C B_{t}$ is set as follows:

$$
C C B_{t}=\max (\min ((\operatorname{Bgr}(t-1)-0.01) \cdot \operatorname{par} C C B+1.25,2.5), 0)
$$

where $\operatorname{Bgr}(t-1)$ is the average growth rate of the credit extended by banks to firms in the previous five periods. In practice, the countercyclical buffer is set between 0 and 2.5\% (as in Basel III regulation) and the value is above the $1.25 \%$ fixed in the baseline scenario, when the credit growth rate exceeds the $1 \%$, and it is below $1.25 \%$ vice versa. We fix the target credit growth rate at $1 \%$ in order to keep it near to the average value observed in the 50 baseline simulations. Consequently, the mean value of the CCB is always around $1.25 \%$ in all the simulations, in order to make comparable the output of the simulations.

The strength of the deviation from the central value of $1.25 \%$ is given by the parameter $\operatorname{par} C C B$. parCCB is set from 2 to 20 with step 2 . For each value of the parameter we perform a small Monte Carlo experiment, replicating the simulation 10 times (for an overall amount of 100 simulations).

We study the effect of the $\mathrm{CCB}$ and of parameter parCCB in terms of the two following output variables: the mean industrial production growth rate, and the volatility of the industrial production's growth rate. These statistics are calculated, for each simulation, on the time series from period 101 to the end of the simulation (period 500).

As already said, the mean value of the $C C B$, computed on the 10 repetitions performed for a given level of $\operatorname{par} C C B$, is always near $1.25 \%$, ranging from $1.233 \%$ to $1.248 \%$ (see the row "mean(mean CCB)" in the upper panel of Table 1). However, the standard deviation, the maximum and the minimum values reached by $C C B_{t}$ in the various simulations change depending on the value of $\operatorname{par} C C B$. In particular, the mean standard deviation has almost a linear growth from a very low $0.037 \%$ when $\operatorname{par} C C B=2$, to $0.355 \%$ when $\operatorname{par} C C B=20$, while the lower bound of 0 and the upper bound of $2.5 \%$ are reached if $\operatorname{par} C C B \geq 12$ (we do not report the standard deviation 
Figure 2: Average cross correlation functions computed on 50 Monte Carlo simulations.
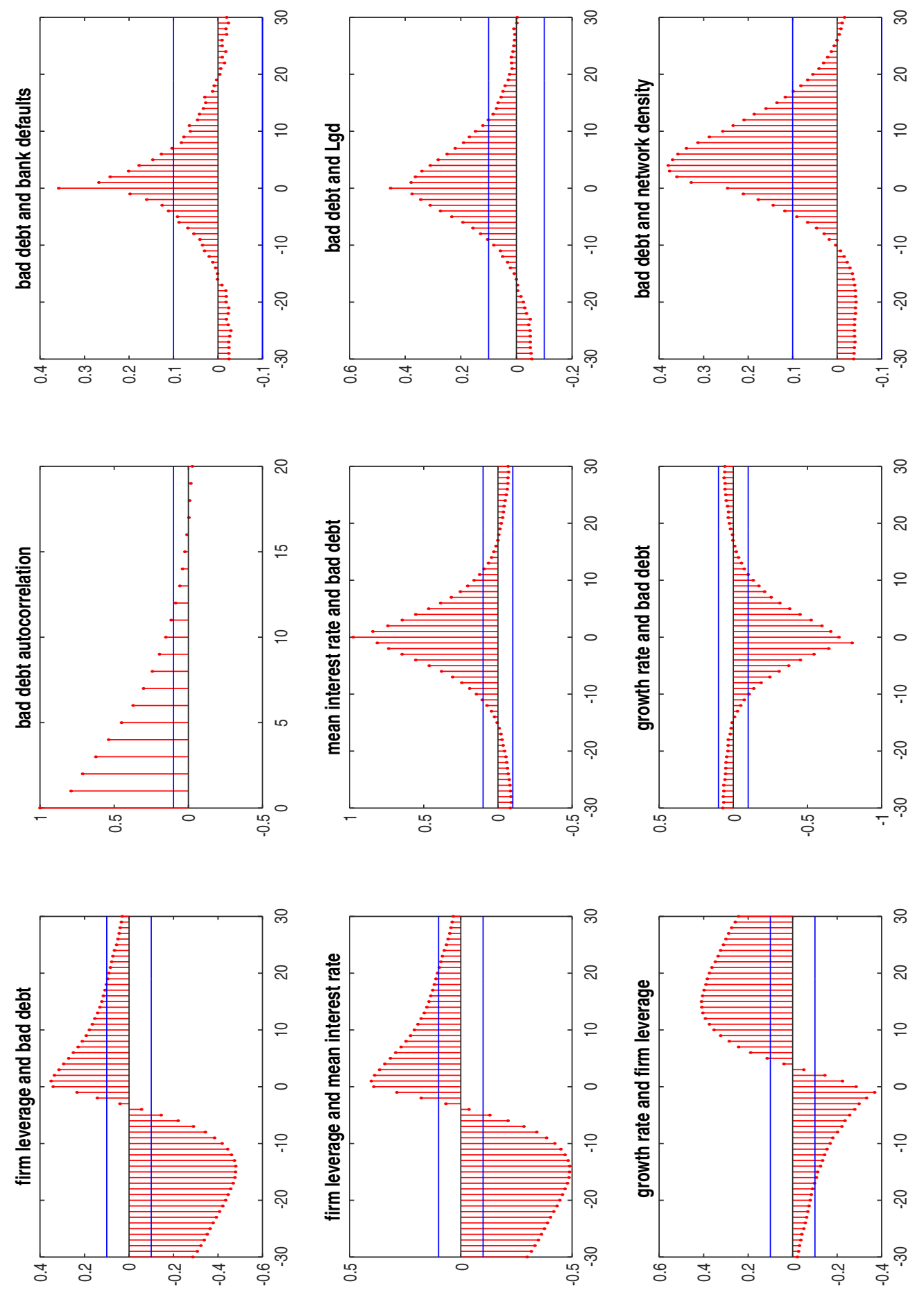
Figure 3: Banks' degree vs. logarithm of banks' assets: with spatial location (left side) and without spatial location (right side).
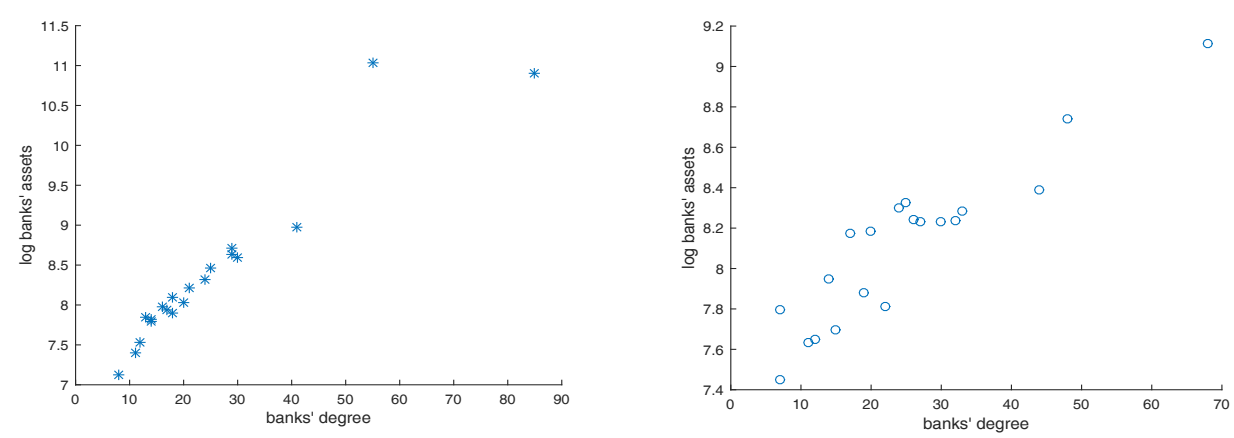

Figure 4: Banks' size and bank-firm credit spatial network: banks are reported on the vertical axis and their sizes are given by the sizes of the colored circles. For each line, which corresponds to a bank, the spatial position of firms borrowing from that bank is represented.

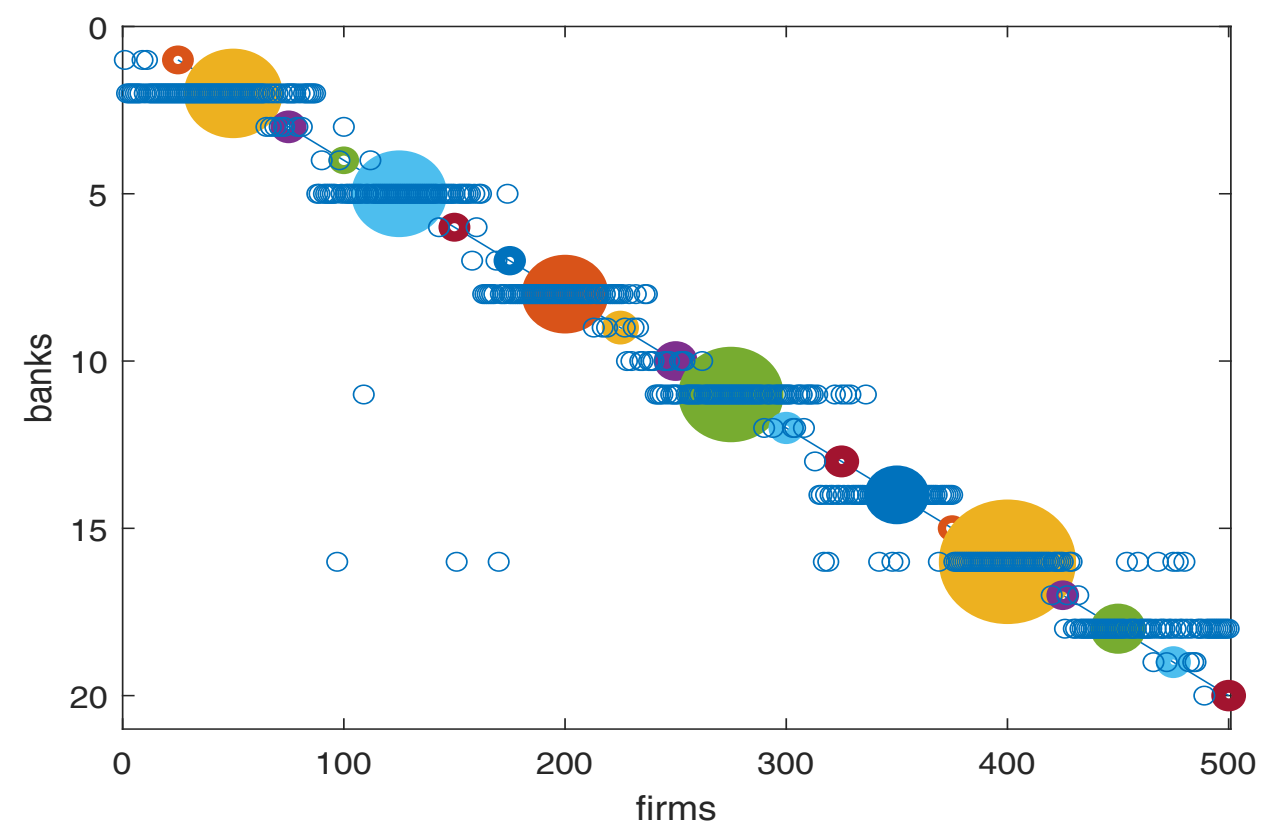


Figure 5: Mean standard deviation of the industrial production growth rate in the simulation with the worst mean industrial production growth rate, for different values of parCCB (from 0 to 20).

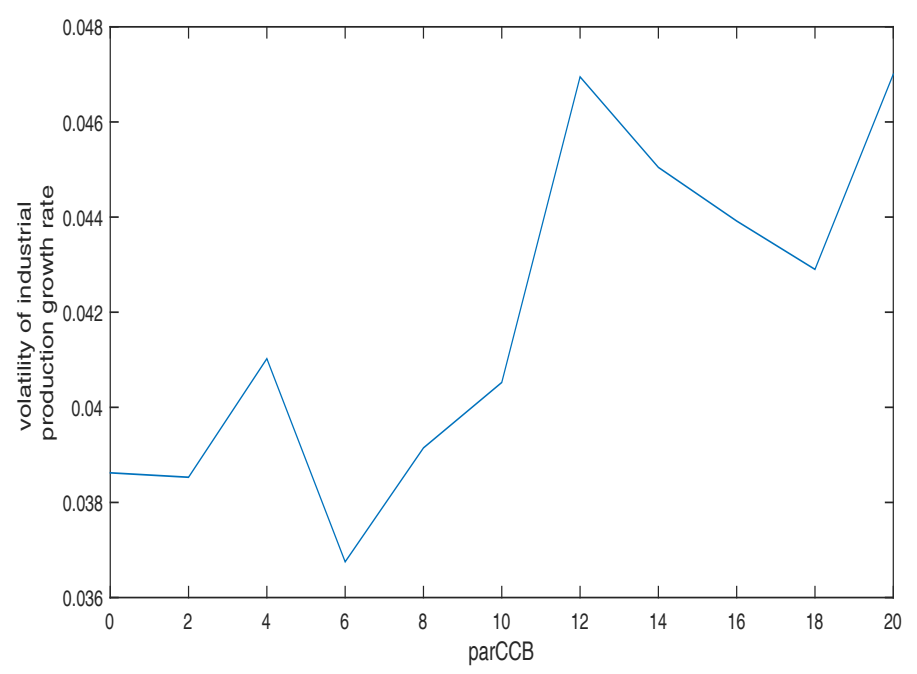

and the maximum of the maximum $\mathrm{CCB}$ in Table 1).

Given that the mean $C C B$ is stable, while its standard deviation grows, the mean industrial production growth rate computed on the 10 simulations is almost unchanged, while the volatility of the industrial production's growth rate shows a light and not significant tendency to increase when $\operatorname{par} C C B$ goes up, as shown in Table 1. Therefore, it seems that the introduction of a countercyclical buffer does not manage to reduce the business cycle fluctuations.

Moreover, we observe that one out of 10 simulations presents a mean industrial production growth rate much lower than the average growth rate observed in the other 9 simulations, that is zero when the others have an average growth rate equal to $0.95 \%$ (and ranging from $0.74 \%$ to $1.13 \%$ ). This simulation also presents a high output volatility. Even focusing on this simulation characterized by many large crises, the countercyclical buffer seems to be useless in reducing the mean standard deviation of the industrial production growth rate when $\operatorname{par} C C B$ is low (below 12) and detrimental when $\operatorname{par} C C B$ is high, as show in Figure 5. 


\subsection{Robustness check with a different business cycle model}

We try to understand if the previous findings are robust to a change in the simulated business fluctuations of the economy. Therefore, we repeat the analysis modifying the $\mathrm{AR}(1)$ parameter of the Equation 9, that is setting $b=0.8$. This value of the parameter is no more in between the real values estimated for Germany and Japan, but is quite near to the 0.84 found on German data. Therefore, for each value of the parameter par $C C B$ (from 0, that is a fixed and non "countercyclical" buffer, to 20 with step 2) we perform again a small Monte Carlo, replicating the simulation 10 times (for an overall amount of 100 simulations), and we study the effect in terms of the mean industrial production growth rate, and the standard deviation of the industrial production's growth rate, calculated from period 101 to 500 for each simulation. We find again that the mean industrial production growth rate is the same for all the groups of simulations with different parCCB values. However, in this case, the CCB seems not to be detrimental for the average standard deviation of the industrial production's growth rate and, moreover, to be effective in reducing the standard deviation when it is most needed, that is in the worst simulations. Indeed, as show in Figure 6, we repeat the analysis on the worst simulation setting $b=0.8$ : the countercyclical buffer seems to be useful in reducing the mean standard deviation of the industrial production growth rate when $\operatorname{par} C C B$ is low, that is between 4 and 8 . Instead, above 12, it is again detrimental.

In order to check if this $\mathrm{U}$ shaped performance is fortuitous, we consider the 50 repetitions of the baseline Monte Carlo simulation and we try to find other simulations with a null mean industrial production growth rate. We observe that the selected simulation is the worst and that there aren't other simulations with this low performance. However, there are some simulations between the majority of "normal" simulations and the one with null average industrial production growth rate. We fix a threshold for the mean industrial production growth rate at $0.35 \%$ and, consequently, we select two other simulations showing low growth. We repeat the same analysis, that is we observe the mean output volatility when $\operatorname{par} C C B$ ranges from 0 to 20 , in the two business cycle settings given by the $\operatorname{AR}(1)$ parameter $b=0.9$ and $b=0.8$.

One of the two simulations confirms the previous findings: when $b=0.9$ the CCB increases the output volatility especially when $\operatorname{par} C C B>10$, while when $b=0.8$ a $\mathrm{U}$ shaped performance emerges. Moreover, in this case the presence of the CCB is always beneficial in reducing output volatility, and the best performance is given by $\operatorname{par} C C B=8$. 
Figure 6: Mean standard deviation of the industrial production growth rate in the simulation with the worst mean industrial production growth rate, for different values of parCCB (from 0 to 20), when $b=0.8$ (the AR(1) parameter).

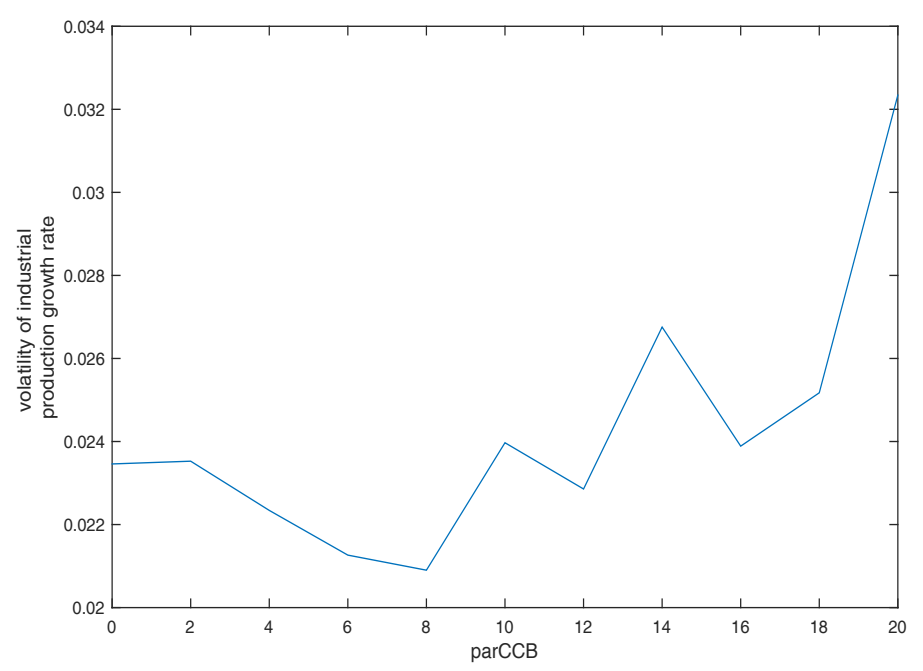

The other simulation partially confirms the previous findings: when $b=0.9$ the presence of the CCB is detrimental because it increases the output volatility especially when $\operatorname{par} C C B$ is relatively high, while when $b=0.8$ the standard deviation of the industrial production growth rate goes up and down without a clear pattern.

\subsection{A possible explanation of the results}

From the experiments performed with $b=0.9$, we can conclude that the countercyclical buffer seems to be useless or even slightly destabilizing, especially when $\operatorname{par} C C B$ is high. In other words, when the adjustment of the $\mathrm{CCB}$ is strong, the output volatility tends to increase instead of being reduced, as aimed by the use of the CCB. A possible explanation for the fact that the CCB seems to be useless could be that the banking system reaches the maximum leverage ratio rarely. Indeed, considering the 50 baseline simulations in periods 101-500, the regulation never constraints the credit amount in 17 out of 50 simulations, and only in 11 simulations the maximum leverage ratio is reached more than 10 times. Therefore, the presence of a CCB could have a weak influence. The number of times in which the regulation is binding is negatively correlated with the average industrial production growth 


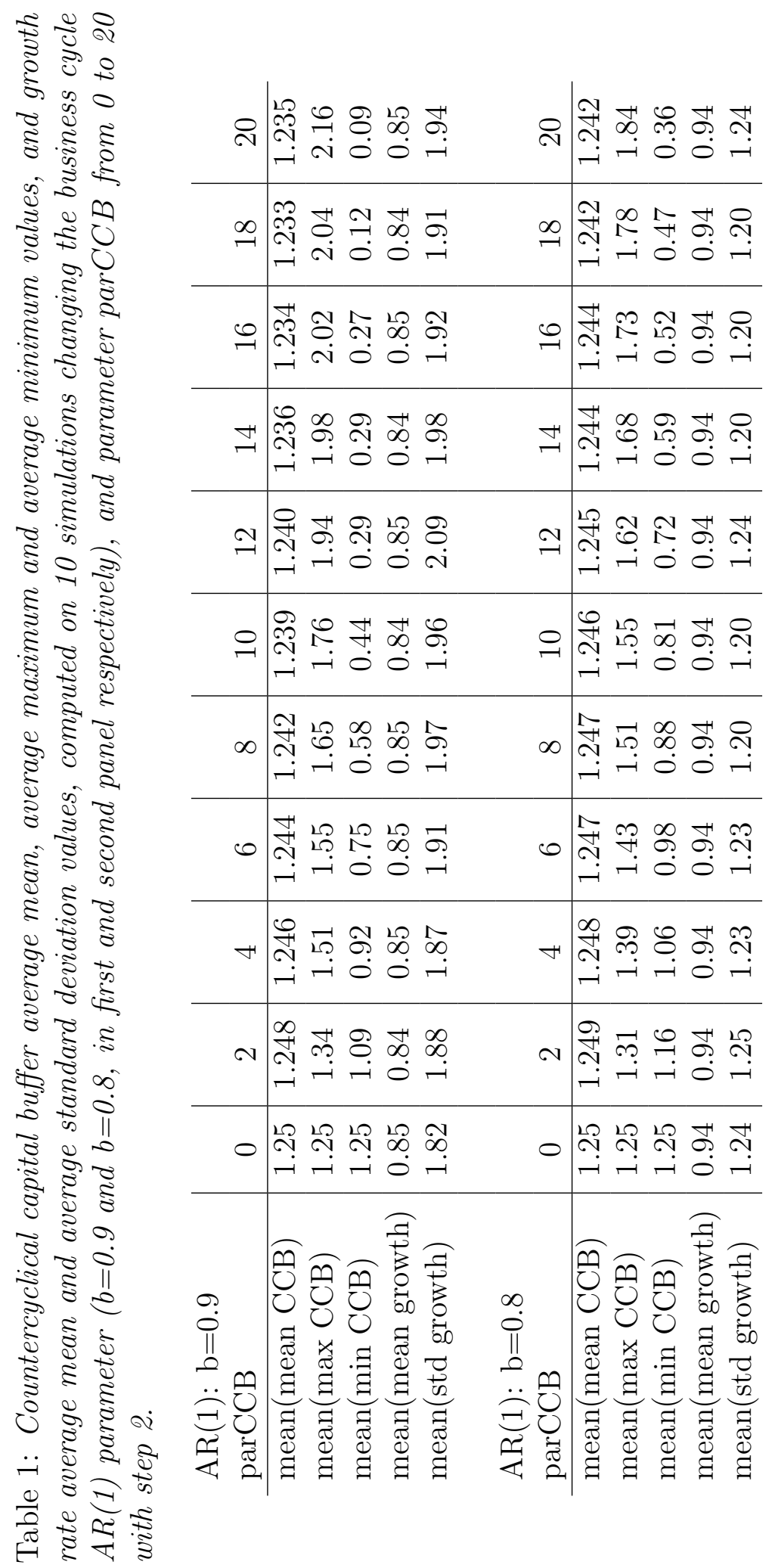


rate $(-0.20)$ and positively correlated with its standard deviation $(+0.77)$. However, even when we focus on the relatively "turbulent" simulations, the previous conclusion does not change when the business cycle is driven by an $\operatorname{AR}(1)$ parameter $b=0.9$.

Instead, the presence of a CCB seems to be useful when the business cycle is driven by an $\operatorname{AR}(1)$ with $b=0.8$. Focusing on the relatively "turbulent" simulations, we also find that the best values for the $\operatorname{par} C C B$ are around the middle of the analyzed range, showing a sort of $U$ shaped relation between par $C C B$ and standard deviation of the industrial production rate of growth. In other words, a CCB that adjusts mildly seems to be useful in stabilizing the output volatility. ${ }^{17}$.

A possible reason of the different performance obtained by the CCB when the parameter of the $\operatorname{AR}(1)$ changes could be that, if the business cycle is quite "sticky" $(b=0.9)$, a credit expansion in a downturn phase could give credit to firms that are not able to survive and, consequently, it enlarges the amount of bad debt (and consequently reduces the banking capital) and all the related crisis mechanisms. Instead, if the business cycle is quite "responsive" ( $b=0.8)$, the CCB can foster the economic recovery, also helping banks in recovering losses thanks to the profits obtained with the new loans.

Some words of cautions are needed about these conclusions. Indeed, in the model the business cycle, that shapes the demand for firms, is not affected by industrial production. Instead, a credit growth for firms should increase the aggregate output and, consequently, the aggregate demand. Therefore, the model should be enriched with a feedback from the aggregate industrial production to GDP and aggregate demand. However, this simplifying assumption is due to the fact that the industrial production is only one of many components of the GDP, therefore it is not trivial to properly assess

\footnotetext{
${ }^{17}$ However, this result is based on few simulations and it should be confirmed by a larger Monte Carlo experiment. We replicate the experiment with $b=0.7$, that is we perform again 10 Monte Carlo simulations for each value of the parameter par $C C B$ from 0 to 20 (with step 2). In this case, the economy works better, with a higher mean growth and a lower growth volatility, because it is easy to recover from a crisis. Consequently, the presence of the CCB is irrelevant: in 5 out of 11 parCCB cases, including the case of no $\mathrm{CCB}(\operatorname{par} C C B=0)$, the average volatility computed on the 10 simulations is 1.04 , and in the other 6 cases it is included between 1.02 and 1.03, that is smaller but with a difference which is not statistically significant. The CCB is irrelevant probably also because the range of variation is smaller compared to the cases of $b=0.8$ and $b=0.9$, indeed, even when $\operatorname{par} C C B=20$, the average (on the 10 simulations) maximum value of the $\mathrm{CCB}$ is 1.78 and the average minimum is 0.56 (quite far from the theoretical maximum and minimum of 2.5 and 0 ). The fact that the CCB is irrelevant confirms the result found with $b=0.8$, when the presence of the CCB was on average neither beneficial nor detrimental. However, the fact that in this scenario we observe a better performance of the economy impedes the analysis on the "bad" simulations, given that in this case there are no "bad" simulations.
} 
this feedback. Moreover, the conclusion that a credit expansion (or the prevention of a credit restriction) could not be useful if the "real economy" is still suffering, could be supported by the recent Italian experience. Indeed, as reported by Tutino et al. (2017), small Italian banks does not restrict credit during financial and sovereign crises, and it causes a large amount of non-performing loans for these banks in the subsequent years, because the Italian economy did not manage to recover from the fall. Consequently, many of these banks were acquired by other banks, many were merged, some were forced to be submitted to the burden sharing (a sort of bail-in) procedure and the whole system was submitted to a regulatory reform from the Italian government, because of a structural lack of capital. The problems of the Italian banking sector in the years after the financial and sovereign crises reinforce the lack of "real" economic recovery, activating the already cited vicious circles. Therefore, as a policy advice, we think that the banking system should be incentivized to enlarge credit extension when there are the seeds of the recovery, that is the business cycle is approaching its lower turning point (the "trough"). However, if the regulator is confident in the banking managers, it can decide to readily use the CCB and leave banks the possibility to extend credit if they face sound firms and have forward-looking expectations of economic recovery, and not to extend credit if they face bad expectations on the future of the "real economy" 18 .

\section{Conclusions}

We presented an agent-based model describing the firm-bank credit market in presence of different business cycle mechanisms, which we exogenously set in order to reproduce various scenarios.

Compared to other models in this literature strand, we improve the mechanism according to which the dividends are distributed, including the possibility of stock repurchase by firms, whose financial structure follows the "dynamic trade-off theory", that is firms have a leverage target. Also, banks change their dividend policy according to their financing needs.

In addition, we locate firms and banks over a space and firms may ask credit

\footnotetext{
${ }^{18}$ In our model, this mechanism is represented by the interest rate that changes following firms' default probability, but it could be further extended including the possible behavior of restricting the amount of lent credit. Moreover, in our model, banks fix the interest rate observing the bad debt ratio of the previous period, that is a backward-looking statistics, while the banks' choice to extend or not credit should be forward-looking. If the choice of the banks to extend credit could be useful for CCB functioning, it could also be the cause of an unsuccessful functioning: banks could be allowed to lend, but they do not want to do it.
} 
to multiple banks, therefore a complex spatial network arises. Indeed, simulations show the emergence of a network in which large banks are characterized by a high connection degree, while small banks present a smaller degree with local customers.

The model reproduces a long list of stylized facts and their dynamic evolution as described by the cross-correlations among model variables. For instance, we find: a pro-cyclical loss-given default rate (when the economy is in recession, banks face more firm defaults and the recovery rate in these default procedures is lower); a positive relationship between firm and bank defaults, a cyclical relationship between firms' leverage and interest rate charged by banks on loans to firms (when firms' leverage grows then interest rates increase, while when interest rates increase then firms' leverage decreases); a positive relationship between firm defaults and interest rates; a cyclical relationship between firms' leverage and defaults (when firms' leverage grows then defaults increase, and when defaults increase then credit is constrained and firms' leverage reduces). Moreover, simulations contain sporadic but very large crises of the banking sector.

However, as explained in the previous Section, the model could be further improved, for instance including a feedback from the endogenous aggregate industrial production to GDP and aggregate demand, that are completely exogenous in the current model. It is reasonable to presume that endogenizing the business cycle, as in many previous papers, would result in a stronger effect of the countercyclical capital buffer, as it is the case in Cincotti et al. (2012) as well as, for instance, in Riccetti et al. (2018). Accordingly, a possible extension of the present model would consider an endogenous business cycle to assess the effectiveness of macroprudential regulation in a more realistic framework. Notwithstanding, in this paper we present a simpler ABM framework in which we aim at isolating the effect of the countercyclical capital buffer under the (strong) hypothesis of an exogenous business cycle, thus artificially changing the business cycle environment from outside the model, in order to evaluate the reaction of the economic and financial system as well as the role of macroprudential regulation. In fact, we show that the effectiveness of the countercyclical capital buffer may change under different phases of the business cycle, even when this is exogenously imposed by the modeler and then absent the feedback tied to an endogenous business cycle.

The model allows the analysis of the dynamic evolution of the credit network in different business cycle phases, and gives us the possibility to test the effectiveness of financial regulation rules. Therefore, we decide to observe the effectiveness of the Basel III countercyclical capital buffer and we find that it is useless or even slightly destabilizing when the business cycle is 
quite "sticky" (higher value of the AR(1) parameter used for the industrial sector operating profit), while it seems to be useful when the business cycle is quite "responsive" (lower value of the AR(1) parameter). This result has a very important implication for Central Banks (and policy makers in general), because it signals the importance of considering the features of the business cycle when designing financial regulation: the same rule could be useful in a country and dangerous in another (no "one size fits all").

\section{References}

[1] Alessandrini P., Presbitero A.F., \& Zazzaro A. (2009), "Banks, Distances and Firms' Financing Constraints", Review of Finance, 13(2), 261-307.

[2] Allen F. \& Gale D. (2000), "Financial contagion", Journal of Political Economy, 108(1), 1-33.

[3] Bargigli, L., Gallegati, M., Riccetti, L. \& Russo, A. (2014). "Network analysis and calibration of the leveraged network-based financial accelerator", Journal of Economic Behavior and Organization, 99(C), 109-125.

[4] Bargigli, L., Riccetti, L., Russo, A. \& Gallegati, M. (2019). "Network calibration and metamodeling of a financial accelerator agent based model", Journal of Economic Interaction and Cordination, on-line version, https://doi.org/10.1007/s11403-018-0217-8.

[5] Bernanke, B., \& Gertler, M. (1989). "Agency costs, net worth and business fluctuations", American Economic Review, 79, 14-31.

[6] Bernanke, B., \& Gertler, M. (1990). "Financial fragility and economic performance", Quarterly Journal of Economics, 105, 87-114.

[7] Bernanke, B., \& Gertler, M. (1995). "Inside the Black Box: The Credit Channel of Monetary Transmission", Journal of Economic Perspectives, $9(4), 27-48$.

[8] Bernanke, B., Gertler, M., \& Gilchrist, S. (1999). "The financial accelerator in a quantitative business cycle framework". In: J. Taylor, \& M. Woodford (Eds.), Handbook of Macroeconomics, Vol. 1 (pp.1341-1393). Amsterdam: North Holland. 
[9] Bottazzi G., De Sanctis A. \& Vanni F. (2020), "Non-performing loans and systemic risk in financial networks", SSRN No. 3539741, https://dx.doi.org/10.2139/ssrn.3539741.

[10] Breevort K.P. \& Hannan T.H. (2006), "Commercial lending and distance: evidence from Community Reinvestment Act data", Journal of money credit and banking, 38(8): 1991-2012.

[11] Caccioli F., Shrestha M., Moore C. \& Doyne Farmer J. (2014), "Stability analysis of financial contagion due to overlapping portfolios", Journal of Banking and Finance, 46: 233-245.

[12] Caiani, A., Godin, A., Caverzasi, E., Gallegati, M., Kinsella, S. \& Stiglitz, J. E., 2016. "Agent based-stock flow consistent macroeconomics: Towards a benchmark model", Journal of Economic Dynamics and Control, 69(C), 375-408.

[13] Cincotti, S. Raberto, M. \& Teglio, A. (2010). "Credit money and macroeconomic instability in the agent-based model and simulator Eurace", Economics - The Open-Access, Open-Assessment E-Journal, 4, 1-32.

[14] Cincotti S., Raberto M., \& Teglio A. (2012), "Macroprudential Policies in an Agent-Based Artificial Economy", Revue de l'OFCE, 0(5): 205234.

[15] Da Silva, M.A., \& Lima, G.T. (2017), "Combining Monetary Policy and Financial Regulation: An Agent-Based Modeling Approach", Journal of Economic Interaction and Coordination, first online (https://doi.org/10.1007/s11403-017-0209-0).

[16] Delli Gatti, D., Gallegati, M., Greenwald, B., Russo, A. \& Stiglitz, J. E. (2006). "Business fluctuations in a credit-network economy", Physica A: Statistical Mechanics and its Applications, 370(1), 68-74.

[17] Delli Gatti, D., Gallegati, M., Greenwald, B., Russo, A., \& Stiglitz, J.E. (2010). "The financial accelerator in an evolving credit network", Journal of Economic Dynamics and Control, 34(9), 1627-1650.

[18] Dosi, G., Fagiolo, G. \& Roventini, A. (2010). "Schumpeter meeting Keynes: A policy-friendly model of endogenous growth and business cycles", Journal of Economic Dynamics and Control, 34(9), 1748-1767.

[19] Fama, E. \& French, K. (2001). "Disappearing dividends: changing firm characteristics or lower propensity to pay?", Journal of Financial Economics, 60(1), 3-43. 
[20] Flannery, M.J., \& Rangan, K.P. (2006). "Partial adjustment toward target capital structures", Journal of Financial Economics, 79(3), 469506.

[21] Frank, M.Z., \& Goyal, V.K. (2008). "Tradeoff and Pecking Order Theories of Debt", In: Espen Eckbo (Eds.), The Handbook of Empirical Corporate Finance (Vol. 2, Chap. 12, pp. 135-202). Amsterdam: Elsevier.

[22] Frank, M.Z., \& Goyal, V.K. (2015). "The Profits-Leverage Puzzle Revisited", Review of Finance, 19(4), 1415-1453.

[23] Greenwald, B., \& Stiglitz, J.E. (1993). "Financial market imperfections and business cycles", Quarterly Journal of Economics, 108, 77-114.

[24] Krug S., Lengnick M., \& Wohltmann H.W. (2014), "The impact of Basel III on financial (in)stability - an agent-based credit network approach", Quantitative Finance, doi: 10.1080/14697688.2014.999701

[25] Lazonick, W. (2013), "Robots Don't Destroy Jobs; Rapacious Corporate Executives Do", Huffington Post Blog, http://www.huffingtonpost.com/william-lazonick/robots-dont-destroyjobs-_b_2396465.html.

[26] Lux T. (2016), "A model of the topology of the bank-firm credit network and its role as channel of contagion", Journal of Economic Dynamics and Control, 66(2016), 36-53.

[27] Neuberger D., \& Rissi R. (2012), "Macroprudential banking regulation: Does one size fit all?", Thuenen-Series of Applied Economic Theory, University of Rostock, Institute of Economics.

[28] Popoyan, L., Napoletano, M., \& Roventini, A. (2013). "Taming macroeconomic instability: Monetary and macro-prudential policy interactions in an agent-based model", Journal of Economic Behavior \& Organization, 134, pp. 117-114.

[29] Riccetti, L., Russo, A., \& Gallegati, M. (2013). "Leveraged NetworkBased Financial Accelerator", Journal of Economic Dynamics and Control, 37(8), pp. 1626-1640.

[30] Riccetti, L., Russo, A., \& Gallegati, M. (2013b). "Unemployment Benefits and Financial Factors in an Agent Based Macroeconomic Model ", Economics: The Open-Access, Open-Assessment E-Journal, 7, 2013-42. 
[31] Riccetti, L., Russo, A., \& Gallegati, M. (2015). "An Agent-Based Decentralized Matching Macroeconomic Model", Journal of Economic Interaction and Coordination, 10(2), pp. 305-332.

[32] Riccetti, L., Russo, A., \& Gallegati, M. (2016). "Stock Market Dynamics, Leveraged Network-Based Financial Accelerator and Monetary Policy", International Review of Economics $\&$ Finance, 43, pp. 509-524.

[33] Riccetti, L., Russo, A., \& Gallegati, M. (2018). "Financial Regulation and Endogenous Macroeconomic Crisis", Macroeconomic Dynamics, 22(4), pp. 896-930.

[34] Russo, A., Catalano, M., Gaffeo, E., Gallegati, M. \& Napoletano, M. (2007). "Industrial dynamics, fiscal policy and R\&D: Evidence from a computational experiment", Journal of Economic Behavior and Organization, 64(3-4), 426-447.

[35] Skinner, D.J. (2008), "The evolving relation between earnings, dividends, and stock repurchases.", Journal of Financial Economics, 87, 582-609.

[36] Stiglitz J. E. (2011), "Rethinking macroeconomics: what failed, and how to repair it", Journal of the European Economic Association, 9(4), 591-645.

[37] Tesfatsion, L. \& Judd, K. L. (2006), Handbook of Computational Economics: Agent-Based Computational Economics, Vol. II, Elsevier.

[38] Tutino, F., Colasimone, C., Brugnoni, G.C., \& Riccetti, L. (2017). "The determinants of lending to customers: evidence from Italy between 2008 and 2012 ", in Bilgin, M.H., Danis, H., Demir, E., Can, U., Empirical Studies on Economics of Innovation, Public Economics and Management, Springer International Publishing AG Switzerland, pp. 57-102. 